\title{
STUDI ALTERNATIF KONSTRUKSI JALAN MENGGUNAKAN KONSTRUKSI TIMBUNAN DENGAN TANAH DASAR DIPERBAIKI MENGGUNAKAN KOMBINASI PRELOADING DAN PREFABRICATED VERTICAL DRAIN
}

\author{
(Studi Kasus: Jalan Lingkar Luar Barat Surabaya STA 1+050 - STA 1+250) \\ Kholifatur Rosidatul Jannah ${ }^{1}$, Arief Alihudien², Suhartinah ${ }^{3}$ \\ Program Studi Teknik Sipil, Fakultas Teknik, Universitas Muhammadiyah Jember ${ }^{1,2,3}$ \\ Jl. Karimata 49, Jember 68121, Indonesia \\ email: kholifatur96@gmail.com
}

\begin{abstract}
The East Java Provincial Government seeks to build a new road network in the form of the Surabaya West Outer Ring Road (JLLB) which has a length of $\pm 19.8 \mathrm{~km}$ with a width of 55 meters. It is expected to break down congestion in the center of Surabaya in order to facilitate access of the population and increase economic growth. The soil condition at this location is soft clay soil which reaches a depth of 21 meters, Soft soil itself has properties that are not technically profitable to support a construction work. In general soft soil has a low carrying capacit, Low permeability and high compressibility cause this land to experience a very large decline and require a long time. One alternative soil improvement to overcome this problem is a combination of preloading methods with prevabricated vertical drain. This method is carried out by overloading the ground with an initial load greater than or equal to the planned building load. This study aims to accelerate the process of land consolidation in order to increase the carrying capacity of the soil so that road construction using heaps can be carried out and analyze the efficiency of the budget plan. Based on the analysis results to reach the final heap height of 4,949 m, Hinitial is needed for $6.78 \mathrm{~m}$ with a total land subsidence of $1.81 \mathrm{~m}$, prior to a very long 100-year consolidation period. So that it is planned to use PVD with a triangular pattern, the distance between PVD of 1 meter with a length of 12 meters which is able to accelerate the time of consolidation of land at $\mathrm{U} 90 \%$ with the final time of compression process 7.5 weeks. Because Hplan > Hcr requires hoarding in stages (Stepped Preloading) with an increase in carrying capacity of $9,896 \mathrm{t} / \mathrm{m} 2$ gives a safety figure of $1.65>1.4$ that is permitted. The total construction cost needed is Rp. 1,124,286,000.00.
\end{abstract}

Keywords: Preloading, Prefabricated vertical drain, Cost efficiency, Land consolidation.

\begin{abstract}
Abstrak
Pemerintah Provinsi Jawa Timur berupaya membangun jaringan jalan baru berupa Jalan Lingkar Luar Barat Surabaya (JLLB) yang memiliki panjang \pm 19,8 km dengan lebar 55 meter. Diharapkan untuk memecah kemacetan di pusat kota Surabaya dalam rangka memfasilitasi akses penduduk dan meningkatkan pertumbuhan ekonomi. Kondisi tanah di lokasi ini adalah tanah lempung lunak yang mencapai kedalaman 21 meter, Tanah lunak itu sendiri memiliki sifat yang tidak menguntungkan secara teknis untuk mendukung pekerjaan konstruksi. Secara umum tanah lunak memiliki kapasitansi rendah, permeabilitas rendah dan kompresibilitas tinggi menyebabkan tanah ini mengalami penurunan yang sangat besar dan membutuhkan waktu yang lama. Salah satu alternatif perbaikan tanah untuk mengatasi masalah ini adalah kombinasi metode preloading dengan drain vertikal yang dibuat sebelumnya. Metode ini dilakukan dengan membebani tanah dengan beban awal lebih besar dari atau sama dengan beban bangunan yang direncanakan. Penelitian ini bertujuan untuk mempercepat proses konsolidasi tanah untuk meningkatkan daya dukung tanah sehingga pembangunan jalan menggunakan timbunan dapat dilakukan dan menganalisis efisiensi rencana anggaran. Berdasarkan hasil analisis untuk mencapai ketinggian timbunan akhir 4,949 m, Hinitial diperlukan untuk 6,78 m dengan total penurunan tanah $1,81 \mathrm{~m}$, sebelum periode konsolidasi 100 tahun yang sangat panjang. Sehingga direncanakan menggunakan PVD dengan pola
\end{abstract}


segitiga, jarak antara PVD 1 meter dengan panjang 12 meter yang mampu mempercepat waktu konsolidasi lahan sebesar U 90\% dengan waktu akhir proses kompresi 7,5 minggu . Karena Hplan> Hcr membutuhkan penimbunan secara bertahap (Stepped Preloading) dengan peningkatan daya dukung $9.996 \mathrm{t} / \mathrm{m} 2$ memberikan angka keamanan 1,65> 1,4 yang diizinkan. Total biaya konstruksi yang dibutuhkan adalah Rp. 1.124.286.000,00.

Kata kunci: Preloading, Drain vertikal vertikal, Efisiensi biaya, Konsolidasi lahan.

\section{PENDAHULUAN}

\subsection{Latar Belakang}

Seluruh wilayah di Indonesia mengalami permasalahan lalu lintas yang sangat kompleks. Surabaya - Sidoarjo - Gresik adalah beberapa kota besar di Indonesia yang mengalami perkembangan sangat pesat dibidang perekonomian, perdagangan, dan perindustrian. Pemerintah provinsi Jawa Timur berupaya membangun jaringan jalan baru berupa Jalan Lingkar Luar Barat Surabaya (JLLB) yang memiliki panjang $\pm 19,8 \mathrm{~km}$ dengan lebar 55 meter. Jalan Lingkar Luar Barat Surabaya diharapkan dapat memecah kemacetan di pusat kota Surabaya.

Pada proyek ini perencana menawarkan konstruksi plat on pile dan pondasi menggunakan tiang pancang. Penggunaan bahan beton umumnya membutuhkan biaya yang mahal. dalam studi ini penulis mengusulkan konstruksi jalan menggunakan alternatif timbunan karena pada umumnya tanah lebih murah dari pada beton mengingat harga dari per $\mathrm{m} 3$ tanah urug yaitu Rp. 296.000 sedangkan harga per $\mathrm{m} 3$ beton ready mix fc' 35 Mpa yaitu Rp. 1.023.410, untuk itu penggunaan tanah sebagai bahan timbunan diharapkan lebih efisien dibandingkan menggunakan beton.

Perencanaan jalan tidak hanya meliputi aspek perencanaan geometrik dan perkerasan jalan akan tetapi yang tidak kalah pentingnya adalah analisis besarnya penurunan yang terjadi pada badan jalan akibat pembebanan lalu lintas dan konsolidasi tanah di bawah perkerasan. Berdasarkan penyelidikan tanah menunjukan bahwa tanah dasar pada lokasi tersebut merupakan tanah lempung lunak (kohesif) yang mencapai kedalaman kurang lebih 21 meter.

Tanah kohesif memiliki sifat plastisitas yang tinggi, kembang susut yang tinggi, daya dukung yang rendah, kandungan air yang tinggi dan sulit terdrainasi karena permeabilitas tanah relatif rendah serta kompresibilitas yang besar menyebabkan tanah mengalami penurunan yang besar dan dalam waktu yang sangat lama. Sehingga apabila konstruksi jalan dibangun diatas tanah dasar lunak tanpa perbaikan tanah, akan terjadi penurunan tanah yang berlangsung sangat lambat sehingga lambat laun terjadi differensial settelment (beda penurunan) yang nyata. Karena beda penurunan ini perkerasan jalan lebih cepat rusak dari pada umur rencana, biaya perawatan jalan menjadi lebih tinggi.

Salah satu metode untuk mengatasi masalah tersebut adalah dengan menggunakan sistem Preloading yang dikombinasikan dengan Prefabricated Vertical Drain (PVD). Preloading merupakan pemberian beban awal yang dilakukan dengan cara memberikan beban berupa timbunan tanah sehingga menyebabkan tanah dasar akan termampatkan sebelum konstruksi didirikan. Prefabricated Vertical Drain (PVD) adalah sistem drainase buatan yang dipasang vertikal sedalam lapisan tanah lunak guna memperpendek panjang aliran dari air pori. Sistem kombinasi ini diharapkan dapat mempercepat proses penurunan tanah dan menaikan daya dukung tanah sehingga konstruksi jalan menggunakan timbunan dapat dikerjakan pada lokasi yang ditinjau.

\subsection{Rumusan Masalah}

Dari latar belakang yang telah diuraikan diatas maka rumusan masalah yang ditinjau antara lain:

1. Berapakah tinggi timbunan pelaksanaan agar dapat mencapai tinggi timbunan yang direncanakan?

2. Berapakah besarnya penurunan tanah dan waktu penurunan apabila tanpa perbaikan tanah?

3. Bagaimana perencanaan perbaikan tanah yang efektif digunakan untuk mempercepat proses konsolidasi tanah lunak? 
4. Bagaimana model pelaksanaan timbunan yang mampu diterapkan untuk desain timbunan pada tanah lunak?

5. Bagaimana efisiensi konstruksi jalan menggunakan plat on pile dan pondasi tiang pancang di bandingkan dengan alternatif konstruksi jalan menggunakan timbunan baik dari segi rencana anggaran biaya?

\subsection{Tujuan} adalah:

Tujuan dari penulisan Tugas Akhir ini

1. Mengetahui tinggi timbunan pelaksanaan agar dapat mencapai tinggi timbunan yang direncanakan

2. Mengetahui besarnya penurunan tanah dan waktu penurunan apabila tanpa perbaikan tanah.

3. Mengetahui perencanaan perbaikan tanah yang efektif digunakan untuk mempercepat proses konsolidasi tanah lunak.

4. Mengetahui model pelaksanaan timbu nan yang mampu diterapkan untuk desain timbunan pada tanah dasar lunak.

5. Mengetahui efisiensi konstruksi jalan menggunakan plat on pile dan pondasi tiang pancang di bandingkan dengan alternatif konstruksi jalan menggunakan timbunan baik dari segi rencana anggaran biaya.

\subsection{Batasan Masalah}

Adapun batasan masalah pada proposal ini, Sebagai berikut:

1. Data tanah yang digunakan untuk melakukan analisa di dapat dari parameter tanah, hasil data pengujian di lapangan dan di laboratorium pada lokasi yang ditinjau.

2. Perbaikan tanah hanya menggunakan Preloading yang dikombinasikan dengan Prefabricated Vertical Drain (PVD).

3. Tidak membahas metode pekerjaan.

4. Kelas jalan yang ditentukan adalah kelas jalan I.

5. Tidak meninjau perhitungan manajem en waktu pelaksanaan proyek (kurva S).

\subsection{Tinjauan Pustaka}

\subsubsection{Tanah Lunak}

Tanah lunak merupakan tanah yang banyak memberikan masalah bagi struktur yang berada di atasnya baik gedung maupun konstruksi perkerasan jalan. Tanah lunak ini dibagi dalam dua tipe yaitu pasir lepas ,lempung lunak, dan gambut. Tanah lunak memiliki sifat berupa daya dukung relatif rendah, nilai kuat geser undrainedrendah, permeabilitas rendah, sifat kembang susut yang besar, dan pemampatan relatif besar yang berlangsu- ng relatif lama. apabila keberadaan tanah lunak ini tidak dikenali dan diselidiki secara berhati-hati dapat menyebabkan ketidak stabilan dan penurunan jangka panjang yang dapat merusak struktur bangunan yang berada di atasnya.

\subsubsection{Konsolidasi Tanah}

Konsolidasi merupakan proses keluarnya air dari dalam pori-pori tanah yang menyebabkan terjadinya perubahan volume tanah (memampat). Peristiwa konsolidasi umumnya dipicu oleh adanya beban/muatan diatas tanah. Muatan tersebut dapat berupa tanah atau konstruksi bangunan yang berdiri diatas tanah. Bila lapisan tanah mengalami beban diatasnya, maka air pori akan mengalir keluar dari lapisan tersebut dan volumenya akan berkurang atau mengalami konsolidasi (Wesley, 1977).

\subsubsection{Besarnya Konsolidasi Tanah Dasar}

Besarnya penurunan untuk tanah terkonsolidasi normal dapat dicari dengan persamaan:

$$
S c=\left[\frac{C c}{1+e o} \log \frac{P o+\Delta P}{P o}\right] x H i
$$

Sedangkan tanah terkosolidasi berlebih besarnya penurunan adalah :

Apabila $(\mathrm{Po}+\Delta \mathrm{P})<\mathrm{Pc}$

$$
\boldsymbol{S c}=\left[\frac{C s}{1+e o} . \log \frac{P o+\Delta P}{P o}\right] x H i
$$

Apabila $(\mathrm{Po}+\Delta \mathrm{P})>\mathrm{Pc}$

$$
S c=\left[\frac{C s}{(1+e o)} \log \frac{P c}{P o}+\right.
$$

$\left.\frac{C c}{(1+e o)} \cdot \log \frac{P o+\Delta P}{P c}\right] x H i$

$\mathrm{Sc}=$ Pemampatan akibat proses konsolidasi $(\mathrm{m}), \mathrm{Cc}=$ indeks kompresi tanah, 
Cs $=$ Indeks pengembangan tanah,

$\mathrm{Po}=$ Tegangan efektif overburden $\left(\mathrm{t} / \mathrm{m}^{2}\right)$,

$\mathrm{Pc}=$ Tegangan efektif prakonsolidasi

$\left(\mathrm{t} / \mathrm{m}^{2}\right)$

$\mathrm{H}=$ Tebal lapisan tanah lembek yang

memampat (m)

$\Delta \mathrm{P}=$ Penambahan tegangan vertikal $\left(\mathrm{t} / \mathrm{m}^{2}\right)$

$\mathrm{e}=$ Angka pori.

\subsubsection{Koefisien Konsolidasi Vertikal (Cv)}

Menentukan kecepatan pengaliran air pada arah vertikal dalam tanah. Karena pada um umnya konsolidasi berlangsung satu arah saja, yaitu arah vertikal, maka koefisien konsolidasi sangat berpengaruh terhadap kecepatan konsolidasi yang akan terjadi. Harga $\mathrm{Cv}$ dapat dicari mengguna- kan persamaan berikut ini :

Dimana :

$$
C v=\frac{T v \cdot H^{2}}{t}
$$

$\mathrm{Cv}=$ koefisien konsolidasi $(\mathrm{cm} 2 / \mathrm{dtk})$

$\mathrm{Tv}=$ faktor waktu tergantung dari derajat konsolidasi $(\mathrm{cm})$

$\mathrm{t}=$ waktu yang dibutuhkan untuk mencapai derajat konsolidasi U\% (dtk)

$\mathrm{H}=$ tebal lapisan tanah $(\mathrm{m})$

\subsubsection{Waktu Konsolidasi Tanah}

Pada tanah yang tidak dikonsolidasi dengan penggunaan PVD, pengaliran yang terjadi hanyalah pada arah vertikal saja. Menurut Terzaghi dalam Das (1985), lamanya waktu konsolidasi dilapangan dapat dihitung sebagai berikut :

$$
t=\frac{T_{\mathbf{9 0} \%} \cdot H^{2}}{C v}
$$

Dimana :

$\mathrm{T} 90 \%=$ Faktor waktu terhadap derajat konsolidasi (U)

$\mathrm{H}=$ panjang maksimum lintasan drainase, untuk drainase dua arah $\mathrm{H} / 2$ sedangkan untuk drainase satu arah $\mathrm{H}(\mathrm{cm})$

$\mathrm{Cv}=$ koefisien konsolidasi $\left(\mathrm{cm}^{2} / \mathrm{dtk}\right)$ $\mathrm{t}=$ waktu konsolidasi (dtk).

\subsubsection{Derajat Konsolidasi}

Derajat konsolidasi tanah (U) adalah perbandingan penurunan tanah pada waktu tertentu dengan penurunan tanah total. Untuk Uv $<60 \%$ maka :

$$
\left(U v=2 \sqrt{\frac{T v}{C v}}\right) \times 100 \%
$$

Untuk Uv > 60\% maka:

$$
\begin{gathered}
U v=\left(100-10^{a}\right) \% \\
\operatorname{dimana}: a=\frac{1.781-T v}{0.933} \\
T_{v}=\frac{t \times C_{v}}{H_{d r}{ }^{2}}
\end{gathered}
$$

\subsubsection{Tinggi Timbunan Awal (Hinitial)}

Untuk terjadinya pemampatan pada tanah dasar maka dilakukan pemberian beban berupa timbunan tanah (surcharge) atau disebut dengan preloading. fungsinya seba- gai beban untuk mempercepat pemampa- tanan, mengisi ruang yang diakibatkan oleh pemampatan dan meningkatkan daya dukung tanah di bawahnya.Setelah pemam patan tanah dasar terjadi, tinggi timbunan awal (Hawal) yang direncanakan akan sesuai dengan dengan tinggi timbunan yang direncanakan (Hakhir). Penentuan tinggi awal pada saat pelaksanaan (dengan memperhatikan penurunan), dapat hitung dengan persamaan berikut:

$$
\begin{aligned}
& \text { Hawal } \mathrm{i}=\frac{\mathrm{q} i+\mathrm{Sci}}{\gamma \text { sat }} \\
& \text { Hakhir } \mathrm{i}=\text { Hawal }- \text { Sci }
\end{aligned}
$$

\subsubsection{Metode Perbaikan Tanah}

Perbaikan dan perkuatan tanah merupakan usaha yang dilakukan dengan tujuan untuk meningkatkan kualitas karakteristik tanah, utamanya parameter kuat geser tanah yang akan mendukung sebuah struktur sehingga mampu menahan beban struktur yang akan dibangun dengan deformasi yang dizinkan.

\subsubsection{Metode Preloading}

Tinggi timbunan kritis beban preloading ini dihitung berdasarkan daya dukung tanah lempung mula - mula. Kekuatan geser tanah lempung akan mempengaruhi tinggi timbunan yang akan dilaksanakan. Daya dukung tanah lempung dalam perencanaan beban preloading dihitung sebagai berikut:

$$
\begin{array}{ll}
\mathrm{qu} & =2 . \mathrm{cu} \\
\mathrm{qu} & =\gamma \mathrm{timb} . \mathrm{Hcr} \\
\mathrm{H} & =(2 . \mathrm{Cu}) /(\gamma \mathrm{timb} . \mathrm{Hcr})
\end{array}
$$

Dimana:

$$
\mathrm{Cu}=\text { kohesi tanah dasar }\left(\mathrm{t} / \mathrm{m}^{2}\right)
$$




$$
\begin{array}{ll}
\gamma \mathrm{tim} & =\text { berat volume tanah timbunan } \\
\left(\mathrm{t} / \mathrm{m}^{3}\right) & =\text { tinggi timbunan kritis }(\mathrm{m})
\end{array}
$$

\subsubsection{Prefabricated Vertical Drain}

Kecepatan konsolidasi tanah berbutir halus yang mudah mampat dapat dipercep- at dengan vertical drain. Drainase vertikal ini memberikan lintasan air pori yang lebih pendek ke arah horisontal.

Derajat konsolidasi rata-rata $\mathrm{U}$ dapat dicari dengan cara :

$$
\mathrm{U}=1-(1-\mathrm{Uh})(1-\mathrm{Uv}) \times 100 \%
$$

Dimana:

$\mathrm{U}=$ derajat konsolidasi tanah rata-rata akibat aliran vertikal dan radial

$\mathrm{Uh}=$ derajat konsolidasi radial

$\mathrm{Uv}=$ derajat konsolidasi vertikal.

Besarnya waktu konsolidasi akibat pemakaian PVD dicari dengan persamaan:

Dimana:

$$
t=\frac{D^{2}}{8 C_{h}} F(n) \ln \left(\frac{1}{1-U_{h}}\right)
$$

$\mathrm{t}=$ Waktu konsolidasi untuk mencapai Uh (dtk)

$\mathrm{D}=$ Diameter equivalen lingkaran $(\mathrm{cm})$ pola bujursangkar $=1,13 \times \mathrm{S}$ pola segitiga $=1,05 \times \mathrm{S}$

$\mathrm{Ch}=$ Koefisien konsolidasi aliran horisontal $\left(\mathrm{cm}^{2} / \mathrm{dtk}\right)$

$\mathrm{Cv}=$ Koefisien konsolidasi aliran vertikal $\left(\mathrm{cm}^{2} / \mathrm{dtk}\right)$

$\mathrm{F}(\mathrm{n})=$ Faktor tahanan akibat jarak PVD.

\section{METODE PENELITIAN}

\subsection{Lokasi Penelitian}

Lokasi Proyek Jalan Lingkar Luar Barat Surabaya (JLLB) berada didaerah Osowilangun, Kecamatan Benowo Kota Surabaya Jawa Timur. Untuk lokasi pembahasan studi kasus terdapat pada STA $1+$ 050 - STA $1+250$.

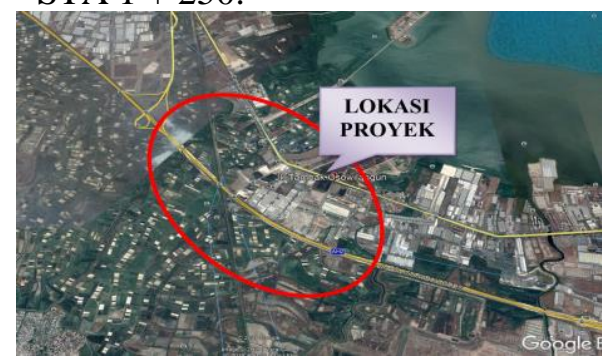

Gambar 1. Layout Lokasi Poyek didaerah

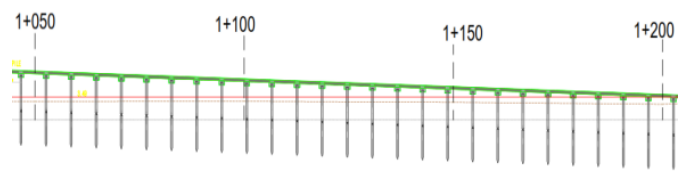

Gambar 2. Existing Jalan

\subsection{Penyelidikan Tanah}

Penyelidikan tanah berupa pengujian dilaboratorium dan dilapangan beberapa parameter yang diperoleh adalah nilai Nspt, kadar air (w), angka pori (e), berat volum $(\gamma)$, $\mathrm{Cu}, \mathrm{Cc}, \quad$ Cv.Data ini digunakan untuk perhitungan pada tugas akhir.

\subsection{Perencanaan beban preloading}

Seluruh beban yang akan diterima oleh tanah dasar baik berupa beban lalu lintas, beban perkerasan, beban timbunan tanah, akan digantikan dengan timbunan tanah. Akibat dari beban timbunan maka akan terjadi penurunan pada tanah dasar, perhitungan waktu dan besarnya penurunan tanpa percepatan, konsolidasi dengan kombinasi preloading dan prefabricated vertical drain, pola yang digunakan pola segitiga dengan jarak divariasikan dan panjang PVD dicari yang paling efektif.

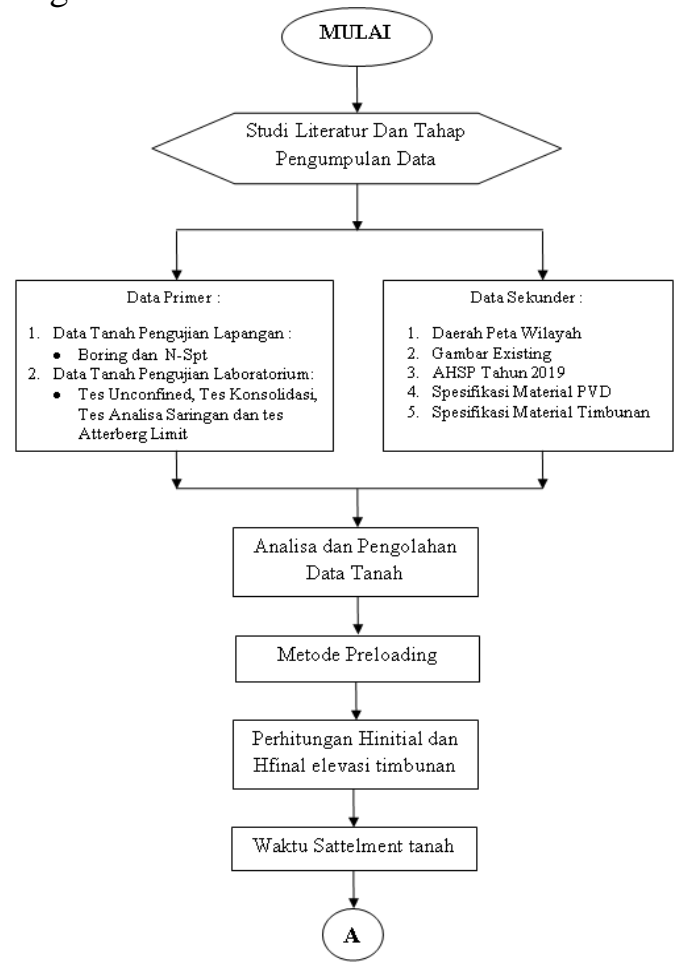




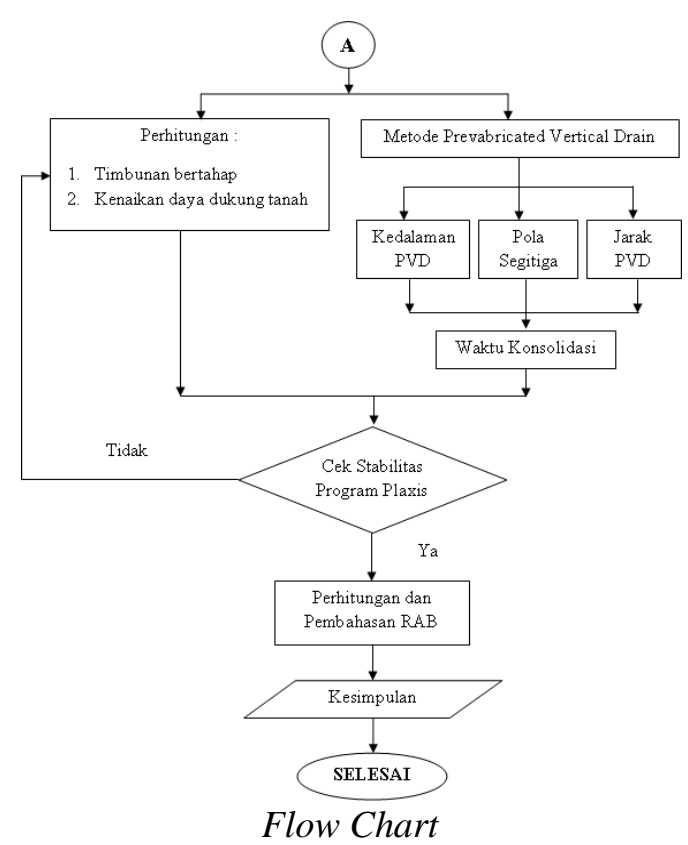

Langkah langkah studi yang dilakukan sebagai berikut:

1. Perhitungan pembebanan awal (Hinitial dan Hfinal)

2. Perhitungan besarnya dan waktu penurunan tanah akibat beban timbunan

3. Penurunan membutuhkan waktu yang lama sehingga dilakukan perbaikan tanah dengan prefabricated vertical drain untuk mempercepat waktu konsolidasi tanah akibat pembebanan.

4. Analisa tinggi timbunan kritis apabila Hrencana > Hkritis maka penimbunan dilakukan dengan cara bertahap.

5. Analisa peningatan nilai $\mathrm{Cu}$ akibat penimbunan bertahap, apakah tanah mampu menerima beban timbunan atau tidak, jika tanah mampu maka penimbunan dilanjutkan hingga $\mathrm{H}_{\text {rencana }}$ tercapai dan apa bila sebaliknya maka penim bunan dihentikan sementara dan tunggu hingga nilai $\mathrm{Cu}$ naik.

\section{HASIL DAN PEMBAHASAN}

\subsection{Data Tanah}

Berikut ini merupakan profil tanah dasar dimana kondisi tanah merupakan lempung lunak hingga mencapai 21 meter.

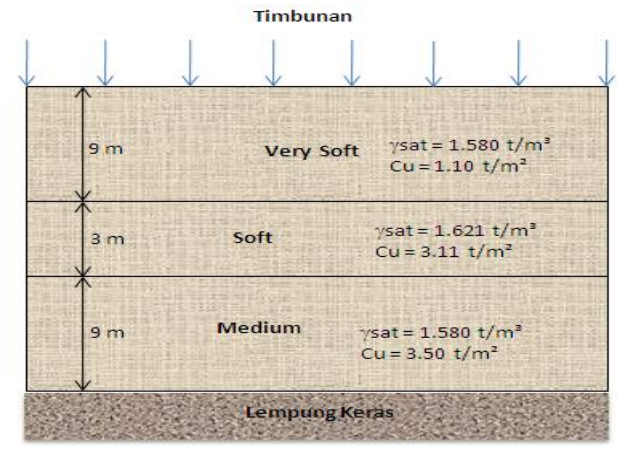

Gambar 3. Profil Tanah Dasar

Tabel 1. Parameter Tanah Dasar

\begin{tabular}{|c|c|c|c|c|}
\hline Karakteristik & & Lapisan 1 & Lapisan 2 & Lapisan 3 \\
\hline Kedalaman $\mathrm{H}$ & meter & 9 & 12 & 21 \\
\hline Kadar Air & $\%$ & 64.310 & 57.590 & 61.180 \\
\hline Angka Pori, E & & 1.622 & 1.521 & 1.622 \\
\hline Berat Jenis, GS & & 2.522 & 2.641 & 2.651 \\
\hline Berat Volume Basah, ybasah & $\mathrm{gr} / \mathrm{cm}^{3}$ & 1.580 & 1.651 & 1.630 \\
\hline Berat Volume Kering $\gamma=\mathrm{d}$ & $\mathrm{gr} / \mathrm{cm}^{3}$ & 0.962 & 1.048 & 1.011 \\
\hline Ysat & $\mathrm{gr} / \mathrm{cm}^{3}$ & 1.580 & 1.651 & 1.630 \\
\hline Po & $\mathrm{Kg} / \mathrm{cm}^{2}$ & 0.580 & 0.976 & 1.259 \\
\hline $\mathrm{PP}_{\mathrm{P}}$ & $\mathrm{Kg} / \mathrm{cm}^{2}$ & 1.160 & 1.130 & 1.180 \\
\hline Index Pemampatan, $\mathrm{Cc}$ & & 1.278 & 1.072 & 1.500 \\
\hline $\mathrm{Cu}$ & $\mathrm{KN} / \mathrm{m}^{3}$ & 10.787 & 30.497 & 34.321 \\
\hline Koef Konsolidasi, $\mathrm{Cv}$ & $\mathrm{cm}^{2} / \mathrm{dtl}$ & 7.8.E-O 4 & 7.9.E-04 & 1.1.E-03 \\
\hline Permeabilitas, $\mathrm{K}$ & $\mathrm{cm}^{2} / \mathrm{dtk}$ & 3.0.E-06 & 3.0.E-06 & 6.0.E-06 \\
\hline
\end{tabular}

\subsection{Data Tanah Timbunan}

Material timbunan direncanakan menggunakan tanah uruk yang berada disekitar lokasi proyek. Berikut ini spesifikasinya:

Tabel 2. Parameter Tanah Dasar

\begin{tabular}{|c|c|c|c|c|}
\hline \multirow[t]{2}{*}{ Parameter } & & & \multicolumn{2}{|c|}{ Areal Geografis } \\
\hline & & & A & B \\
\hline Berat Isi & $\gamma$ & $\mathrm{kN} / \mathrm{m}^{3}$ & 18 & 20 \\
\hline $\begin{array}{l}\text { Kuat geser tak } \\
\text { terdrainase }\end{array}$ & $\mathrm{C}_{u}$ & $\mathrm{kN} / \mathrm{m}^{2}$ & 100 & 100 \\
\hline \multicolumn{5}{|l|}{$\begin{array}{c}\text { Parameter } \\
\text { tegangan efektif }\end{array}$} \\
\hline Kohesi & $\mathrm{C}^{\prime}$ & & 10 & 5 \\
\hline Friksi & $\phi$ & & 35 & 30 \\
\hline A Jan & gian & batuan $\mathrm{v}$ & & \\
\hline B Sur & $\begin{array}{l}\text { bag } \\
\text { amor }\end{array}$ & Ir, Kalim & Kepul & dones \\
\hline
\end{tabular}

\subsection{Geometri Timbunan}

Data-data perencanaan dari geometri timbunan adala sebagai berikut:

- Tinggi timbunan hingga $4 \mathrm{~m}$.

- Lebar atas timbunan $20 \mathrm{~m}$.

- Kemiringan timbunan 30。

\subsection{Penambahan Tegangan Vertikal $(\Delta p)$}

Penambahan tegangan berasal dari beban timbunan, dalam perhitungan ini beban pemisalan timbunan yang dipakai adalah $\mathrm{q}=5$ $\mathrm{t} / \mathrm{m} 2$. Untuk menghitung $\Delta \mathrm{p}$ megguna kan persamaan, dengan data berikut. 
Lapisan 1:

$$
\begin{aligned}
& \mathrm{a}=7.5 \mathrm{~m} \\
& \mathrm{~b}=10 \mathrm{~m} \\
& \mathrm{I}_{1}=0.493
\end{aligned}
$$

Menghitung $\Delta \mathrm{p}$ memerlukan nilai $\mathrm{I}$, dan distribusi tegangan pada timbunan dianggap distribusi bentuk trapezium, sedangkan nilai I didapat dari Persamaan grafik NAVFAC dengan distribusi bentuk trapesium yaitu $\mathrm{I}=49$ . Penggunaan grafik NAVFAC (gambar 2.2) hanya untuk setengah timbunan, jadi untuk perhitungan timbunan yang utuh nilai I dikalikan 2.

$$
\begin{aligned}
\Delta \mathrm{p} \text { lap1 } & =2 \times \mathrm{I}_{1} \times \mathrm{q} \\
& =2 \times 0,493 \times 3 \\
& =2.96 \mathrm{t} / \mathrm{m}^{2}
\end{aligned}
$$

Tabel 3. Penambahan Tegangan Akibat $\mathrm{q}$

\begin{tabular}{|c|c|c|c|}
\hline $\begin{array}{c}\text { Beban q } \\
\left(\text { ton } / \mathrm{m}^{2}\right)\end{array}$ & $\begin{array}{c}\Delta \mathrm{p} \text { lapisan 1 } \\
\mathrm{t} / \mathrm{m}^{2}\end{array}$ & $\begin{array}{c}\Delta \mathrm{p} \text { lapisan 2 } \\
\mathrm{t} / \mathrm{m}^{2}\end{array}$ & $\begin{array}{c}\Delta \mathrm{p} \text { lapisan 3 } \\
\mathrm{t} / \mathrm{m}^{2}\end{array}$ \\
\hline 3 & & & \\
\hline 5 & 2.96 & 2.66 & 2.24 \\
\hline 7 & 4.93 & 4.43 & 3.74 \\
\hline 9 & 6.90 & 6.20 & 5.24 \\
\hline 11 & 8.87 & 7.97 & 6.73 \\
\hline 13 & 10.84 & 9.74 & 8.23 \\
\hline
\end{tabular}

\subsection{Settlement Tanah Dasar Akibat q}

Dalam menghitung penurunan tanah harus diperhatikan dari sifat tanahnya, apakah normally consolidated atau over consolidated. diperoleh nilai OCR > 1 maka kita gunakan sifat tanah over consolidated. sifat over consolidated sendiri juga harus memperhatikan apakah Po' $+\Delta \mathrm{p} \leq \mathrm{Pc}^{\prime}$ atau Po' $+\Delta \mathrm{p}>\mathrm{Pc}^{\prime}$. Pehitungan untuk q design beban 3 ton $/ \mathrm{m}^{2}$ yang menghasilkan sattlement sebesa $1.37 \mathrm{~m}$ bisa dilihat di Tabel 4 . , untuk design beban selanjutnya tedapat pada Tabel 5 ..

Tabel 4. Hasil Besarnya Settlement Akibat Beban Desain 3 ton $/ \mathrm{m}^{2}$

\begin{tabular}{|c|c|c|c|c|c|c|c|c|c|c|}
\hline $\begin{array}{c}\text { Tebal } \\
\text { lapisan } \\
\text { tanah }\end{array}$ & $\mathrm{Z}$ & $\mathrm{e} 0$ & $\mathrm{Cs}$ & $\mathrm{Cc}$ & $\mathrm{pc}$ & $\mathrm{po}$ & $\mathrm{I}$ & $\Delta \mathrm{p}$ & $\Delta \mathrm{p}+\mathrm{po}$ & $\mathrm{Sc}$ \\
\hline $\mathrm{m}$ & $\mathrm{m}$ & & & & $\mathrm{tm}^{3}$ & $\mathrm{tm}^{3}$ & & $\mathrm{tm}^{3}$ & $\mathrm{tm}^{3}$ & $\mathrm{M}$ \\
\hline 9 & 4.5 & 1.622 & 0.256 & 1.278 & 4.61 & 2.61 & 0.493 & 2.96 & 5.57 & 0.73 \\
\hline 3 & 1.5 & 1.521 & 0.214 & 1.072 & 8.20 & 6.20 & 0.443 & 2.66 & 8.85 & 0.16 \\
\hline 9 & 4.5 & 1.622 & 0.300 & 1.500 & 12.01 & 10.01 & 0.374 & 2.24 & 12.25 & 0.48 \\
\hline \multicolumn{8}{|c|}{ Total Sci } \\
\hline \multicolumn{10}{|c|}{}
\end{tabular}

Tabel 5. Hasil Pemampatan Terhadap Beban Design (q)

\begin{tabular}{|c|c|}
\hline $\mathrm{q}$ (beban) & $\mathrm{Sc}$ \\
\hline ton $/ \mathrm{m} 2$ & $\mathrm{~m}$ \\
\hline 3 & 1.37 \\
\hline 5 & 1.53 \\
\hline 7 & 1.65 \\
\hline 9 & 1.76 \\
\hline 11 & 1.85 \\
\hline 13 & 1.92 \\
\hline
\end{tabular}

\subsection{Analisa Beban Diatas Timbunan 3.6.1 Beban Perkerasan}

Di rencanakan kelas jalan 1, Jenis struktur perkerasan yang di pakai adalah struktur perkerasan lentur (lalulintas berat) pada timbunan.

Tabel 6. Hasil beban perkerasan

\begin{tabular}{|c|l|c|c|c|}
\hline No. & $\begin{array}{c}\text { Jenis } \\
\text { Perkerasan }\end{array}$ & $\begin{array}{c}\text { Tebal } \\
(\mathrm{H})\end{array}$ & $\begin{array}{c}\text { Berat } \\
\text { Jenis }\end{array}$ & Beban Perkerasan \\
\hline & & $\mathrm{m}$ & $\mathrm{t} / \mathrm{m}^{3}$ & $\mathrm{t} / \mathrm{m}^{2}$ \\
\hline 1 & AC WC & 0.04 & 2.2 & 0.088 \\
\hline 2 & AC BC & 0.06 & 2.2 & 0.132 \\
\hline 3 & AC Base & 0.245 & 2.2 & 0.490 \\
\hline 4 & LPA & 0.30 & 2.1 & 0.630 \\
\hline \multicolumn{5}{|c|}{ Total } \\
\hline
\end{tabular}

\subsubsection{Beban Lalulintas}

Tabel 7. Hasil beban lalulintas

\begin{tabular}{|c|c|c|}
\hline \multirow{2}{*}{$\begin{array}{c}\text { Kelas } \\
\text { Jalan }\end{array}$} & \multicolumn{2}{|c|}{ Beban Lalu Lintas } \\
\cline { 2 - 3 } & $(\mathrm{kPa})$ & (ton $\left./ \mathrm{m}^{2}\right)$ \\
\hline I & 15 & \\
\hline II & 12 & 1.53 \\
\hline III & 12 & 1.22 \\
\hline
\end{tabular}

Beban lalulintas dan beban pekerasan menyebabkan penurunan untuk itu harus diperhitungkan sebagai tambahan beban merata, kemudian dapat dikorelasikan dalam tinggi embakment (timbunan) tambahan sehingga pada akhir konsolidasi tinggi tambahan tersebut akan dibongkar.

Tabel 8. Korelati beban ke $\mathrm{H}_{\text {timbunan }}$

\begin{tabular}{|l|c|c|c|}
\hline Jenis Beban & $\begin{array}{c}\text { Beban } \\
\left.\text { (ton } / \mathrm{m}^{2}\right)\end{array}$ & $\begin{array}{c}\gamma \text { timbunan } \\
\left.\text { (ton } / \mathrm{m}^{3}\right)\end{array}$ & $\begin{array}{c}\text { Total } \mathrm{H} \\
\text { bongkar } \\
(\mathrm{m})\end{array}$ \\
\hline Perkerasan & 1.340 & 1.8 & 0.744 \\
\hline Lalulintas & 1.530 & 1.8 & 0.850 \\
\hline \multicolumn{3}{|c|}{ Total } & $\mathbf{1 . 5 9 4}$ \\
\hline
\end{tabular}

Hakhir lapangan $=\mathrm{H}_{\text {timbunan }}+\mathrm{H}_{\text {bongkar }}$ $=3.355+1.594$ 


$$
=4.949 \text { meter }
$$

\subsection{Tinggi initial dan Tinggi final}

Untuk menentukan tinggi timbunan pelaksanaan $\left(\mathrm{H}_{\text {initial }}\right)$ agar nantinya tinggi timbunan sesuai dengan yang direncanakan (Hfinal). Berikut perhitunganya:

$\mathrm{H}_{\text {initial }}=\mathrm{qi}+\mathrm{Sci} / \gamma \mathrm{sat}=3+1.37 / 1=2.43$ meter $\mathrm{H}_{\text {final }}=\mathrm{H}$ awal $-\mathrm{Sci}=2.43-1.37=1.06$ meter

Tabel 9. $\mathrm{H}_{\text {Initial }}, \mathrm{H}_{\text {Final }}$ Akibat Beban q

\begin{tabular}{|c|c|c|c|c|}
\hline \multirow{2}{*}{ No. } & $\begin{array}{c}\text { Beban } \mathbf{q} \\
\left(\mathbf{t} / \mathbf{m}^{2}\right)\end{array}$ & $\begin{array}{c}\text { Settelmen Akibat } \mathbf{q} \\
(\mathbf{m})\end{array}$ & $\begin{array}{c}\mathbf{H}_{\text {initial }} \\
(\mathbf{m})\end{array}$ & $\begin{array}{c}\text { Tinggi Final } \\
\text { Finished Grade } \\
(\mathbf{m})\end{array}$ \\
\cline { 2 - 5 } & DESIGN & CALCULATION & $(\mathbf{B}+\mathbf{C}) /$ ytim & $\mathbf{D}-\mathbf{C}$ \\
\hline $\mathbf{A}$ & $\mathbf{B}$ & $\mathbf{C}$ & $\mathbf{D}$ & $\mathbf{E}$ \\
\hline 1 & 3 & 1.37 & 2.43 & 1.06 \\
\hline 2 & 5 & 1.53 & 3.63 & 2.10 \\
\hline 3 & 7 & 1.65 & 4.81 & 3.15 \\
\hline 4 & 9 & 1.76 & 5.98 & 4.22 \\
\hline 5 & 11 & 1.85 & 7.14 & 5.29 \\
\hline 6 & 13 & 1.92 & 8.29 & 6.37 \\
\hline
\end{tabular}

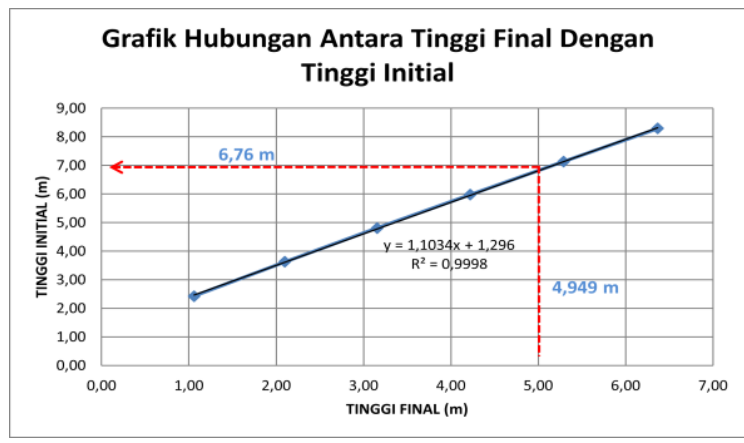

Gambar 4.graik $\mathrm{H}_{\text {Initial}}, \mathrm{H}_{\text {Final }}$

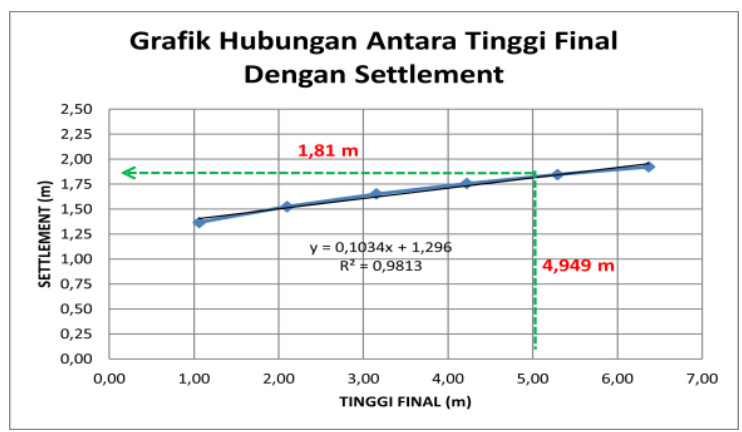

Gambar 5.H Initial $_{\text {dan Settlement }}$

Jadi, untuk mencapai Hfinal 4,949 meter maka tinggi timbunan awal sebesar 6.76 meter dengan total penurunan yang harus dihilangkan 1.82 meter.

\subsection{Waktu Penurunan Tanpa Perbaikan}

Hal ini dilakukan untuk menentukan perlu atau tidaknya dilakukan perbaikan tanah, Karena tanah berlapis dengan ketebalan yang berbeda makan untuk harga $\mathrm{Cv}_{\text {gabungan }}$.

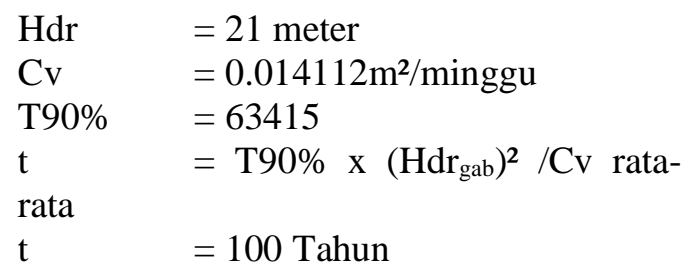

Waktu penurunan berlangsung sangat lama padahal dalam suatu proyek tidak mungkin menunggu selama itu. Untuk mempercepat waktu konsolidasi maka dibutuhkan adanya pemasangan Prefabricated Vertical Drain, dengan seperti ini diharapkan penurunan tanah total yang harus dihilangkan pada massa konstruksi dapat tercapai dengan waktu berlangsung relatif sangat singkat.

\subsection{Perencanaan PVD}

\subsubsection{Menentukan Kedalaman PVD :}

Tabel 10. perbandingan kedalaman PVD dan rate of settlement

\begin{tabular}{|c|c|c|c|c|c|c|c|c|}
\hline \multirow{2}{*}{\multicolumn{2}{|c|}{$\begin{array}{l}\text { Tebal Lapisan } \\
\text { Terkonsolidasi }\end{array}$}} & \multirow{2}{*}{\multicolumn{3}{|c|}{$\begin{array}{c}\text { Settlemen Akibat } \\
\text { Timbunan } \\
\text { Penurunan Jangka } \\
\text { Pendek }\end{array}$}} & \multirow{2}{*}{\multicolumn{3}{|c|}{$\begin{array}{c}\text { Setelah } 10 \text { Tahun } \\
\text { Penurunan Jangka } \\
\text { Panjang }\end{array}$}} & \multirow{3}{*}{$\begin{array}{r}\text { Rate of } \\
\text { Settleme } \\
\text { nt }\end{array}$} \\
\hline & & & & & & & & \\
\hline $\begin{array}{c}\text { Tota } \\
1\end{array}$ & $\begin{array}{l}\text { Kedalam } \\
\text { an PVD }\end{array}$ & Total & $\begin{array}{c}\text { Sedalaman } \\
\text { PVD }\end{array}$ & Sisa & TV & Uv & $\begin{array}{l}\begin{array}{c}\text { Settle } \\
\text { ment }\end{array} \\
\end{array}$ & \\
\hline $\mathrm{m}$ & $\mathrm{m}$ & $\mathrm{m}$ & $\mathrm{m}$ & $\mathrm{m}$ & & $\%$ & $\mathrm{~m}$ & $\mathrm{~cm} / \operatorname{tah} \mathrm{n}$ \\
\hline & & & & & & & & \\
\hline 21 & 9 & 1.82 & 1.08 & 0.74 & 0.63 & 28.42 & 0.21 & 2.10 \\
\hline 21 & 12 & 1.82 & 1.27 & 0.54 & 0.63 & 28.42 & 0.15 & 1.54 \\
\hline 21 & 21 & 1.82 & 1.82 & 0.00 & 0.63 & 28.42 & 0.00 & 0.00 \\
\hline
\end{tabular}

Hasil analisa rate of settlement didapat penurunan setelah masa konstruksi 1.54 $\mathrm{cm} /$ tahun $<2 \mathrm{~cm} /$ tahun hal ini sesuai dengan batas penurunan yang di izinkan untuk kelas jalan 1, sehingga kedalaman rencana vertikal drain yang efektif untuk mempercepat waktu penurunan yaitu dipasang hingga kedalaman 12 meter.

\subsubsection{Perhitungan Derajat Konsolidasi Vertikal (Uv)}

Besarnya Uv diasumsikan $<60 \%$ sehingga digunakan Persamaan (6). nilai Uv membutuhkan faktor nilai Tv dengan persamaan (8). dalam perencanaan ini t (waktu) dibuat dalam satuan minggu.

Tabel 11. Hasil nilai Tv dan Uv

\begin{tabular}{|c|c|c|c|c|}
\hline t & HDR & CV & TV & UV \\
\hline Minggu & meter & $\mathbf{m}^{2} /$ minggu & & \\
\hline 1 & 12 & 0.047325 & 0.00033 & 0.02046 \\
\hline 2 & 12 & 0.047325 & 0.00066 & 0.02894 \\
\hline 3 & 12 & 0.047325 & 0.00099 & 0.03544 \\
\hline 4 & 12 & 0.047325 & 0.00131 & 0.04092 \\
\hline 5 & 12 & 0.047325 & 0.00164 & 0.04575 \\
\hline 6 & 12 & 0.047325 & 0.00197 & 0.05012 \\
\hline 7 & 12 & 0.047325 & 0.00230 & 0.05413 \\
\hline 8 & 12 & 0.047325 & 0.00263 & 0.05787 \\
\hline 9 & 12 & 0.047325 & 0.00296 & 0.06138 \\
\hline 10 & 12 & 0.047325 & 0.00329 & 0.06470 \\
\hline
\end{tabular}




\subsubsection{Perhitungan Derajat Konsolidasi Horisontal (Uh)}

Derajat konsolidasi horizontal. Dalam perhitungan Uh dibutuhkan bebe-r apa parameter seperti $\mathrm{F}(\mathrm{n}), \mathrm{Ch}$, dan D. Untuk parameter $\mathrm{Ch}$ dibutuhkan perban- dingan parameter koefisien permeabilitas horisontal $(\mathrm{Kh})$ dan koefisien permeabilitas vertikal $(\mathrm{Kv})$, namun hal tersebut harus berdasarkan penelitian. Jadi dalam perencanaan iniperbandingan $\mathrm{Kh}$ dan $\mathrm{Kv}$ berdasarkan perkiraan interval 2-5.

Perhitungan berikut menggunakan pola pemasangan segitiga, panjang PVD $12 \mathrm{~m}$ dan variasi jarak $(0.8 \mathrm{~m} ; 1 \mathrm{~m} ; 1.5 \mathrm{~m} ; 2 \mathrm{~m})$.

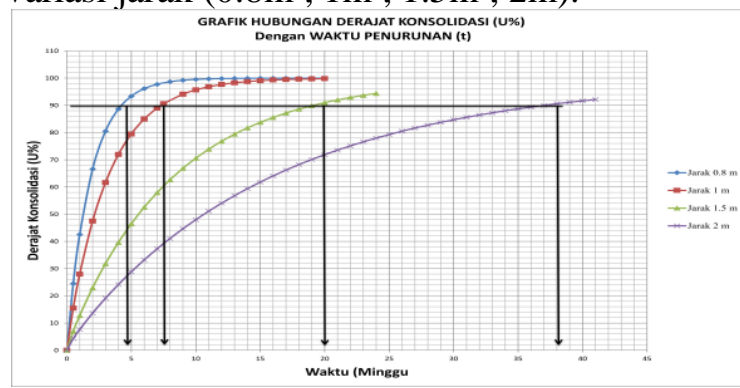

Gambar 6.Grafik U\% dan Waktu

Maka dipilih pemasangan PVD pola segitiga dengan jarak pemasangan 1 meter dan derajat konsolidasi rata-rata (U) yang terjadi adalah 90,577\% dengan waktu akhir proses pemampatan tanah dengan beban rencana yaitu 7.5 minggu.

\subsection{Perhitungan $\mathbf{H}_{\text {kritis }}$}

Untuk melihat stabilitas atau kemampuan tanah dasar dalam menerima beban dari timbunan agar tidak tejadi keruntuhan pada saat tahap penimbunan di laksanakan. untuk perhitungan ini di gunakan software program PLAXIS 2D, dapat di lihat pada Gambar 7.berikut :

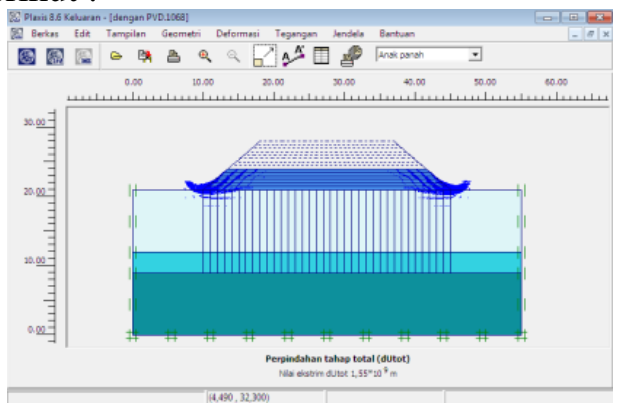

Gambar 7.Tinggi timbunan kritis
Dengan aplikasi PLAXIS diperoleh $\mathrm{H}_{\text {kritis }}$ 3 meter dengan nilai keamanan $1.030>1$ yang artinya tanah dasar mampu menerima beban timbunan tanpa terjadi keruntuhan. Karena nilai $\mathrm{H}_{\text {rencana }}>\mathrm{H}_{\text {kritis}}$, maka beban Preloading di letakkan secara bertahap (Stepped Preloading).

Setelah dilakukan analisa terhadap kenaikan daya dukung tanah pada Tabel 12 . Akibat timbunan bertahap setinggi 3 meter terjadi kenaikan daya dukung tanah $\mathrm{Cu}$ baru sebesar $2.121 \mathrm{t} / \mathrm{m}^{2}$. sehingga dapat dihitung tahap penimbunan selanjutnya untuk mendapatkan tinggi timbunan sesuai rencana. digunakan software program PLAXIS 2D, dapat di lihat pada Gambar 8.berikut :

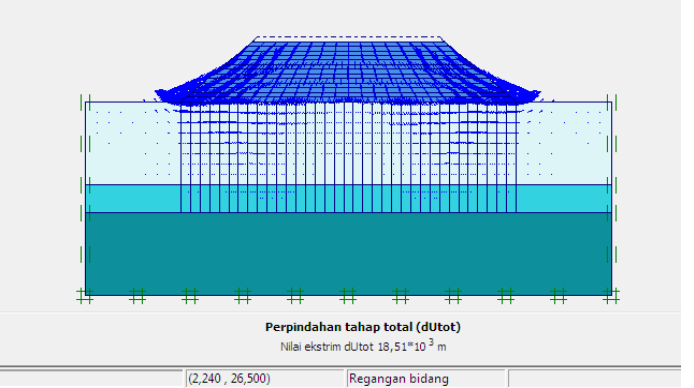

Gambar 8.Tinggi Timbunan Kritis

Setelah dilakukan analisa penimbunan bertahap diperoleh tinggi timbunan yang sesuai dengan $\mathrm{H}_{\text {rencana }} 6.76$ meter, di dapat nilai keamanan $1.651>1$ yang mana telah mencapai Savety Factor yang diizinkan, sehingga tanah dasar telah mampu menerima beban timbunan tanpa terjadi keruntuhan. Maka pada tahap berikutnya penimbunan bertahap telah mencapai $\mathrm{H}_{\text {rencana }}$ dan dapat dilaksanakan. Lihat Tabel 13.

\subsection{Perhitungan Kenaikan Daya Dukung Tanah}

Bertujuan untuk menentukan apakah tanah dasar cukup mampu memikul beban timbunan tahapan selanjutnya dengan niai $\mathrm{Cu}$ baru yang diperoleh dari penimbunan sebelumnya. Direncanakan jarak PVD 1 meter, pola pemasangan PVD segitiga dan panjang PVD 12 meter. Maka dilakukan analisa perhitungan peningkatan nilai $\mathrm{Cu}$ akibat penimbunan bertahap setinggi $3 \mathrm{~m}$. 
Tabel 12. Peningkatan Nilai Cu Akibat Penimbunan bertahap 3 meter

\begin{tabular}{|c|c|c|c|c|}
\hline $\begin{array}{c}\text { Tahapan } \\
\text { Penimbunan }\end{array}$ & $\begin{array}{c}\text { Umur } \\
\text { Timbunan, } \\
\mathrm{t} \\
\text { (Minggu) }\end{array}$ & $\begin{array}{c}\text { Derajat } \\
\text { Konsolidasi } \\
(100 \%)\end{array}$ & $\begin{array}{c}\text { Tegangan } \\
\text { Efektif Pada } \\
\text { lapisan yang } \\
\text { ditinjau U = } \\
100 \% \\
\end{array}$ & $\begin{array}{c}\text { Peningkatan } \\
\text { Nilai Cu } \\
\Delta \mathrm{P} \text { Pada Ui } \%\end{array}$ \\
\hline Tanah Asli & & 100 & $P_{0}=2.61$ & 2.61 \\
\hline $0-0.5 \mathrm{~m}$ & 6 & 79.466 & 3.46 & 0.66 \\
\hline $0.5-1 \mathrm{~m}$ & 5 & 71.939 & 4.30 & 1.88 \\
\hline $1-1.5 \mathrm{~m}$ & 4 & 61.627 & 5.12 & 1.61 \\
\hline $1.5-2 \mathrm{~m}$ & 3 & 47.474 & 5.92 & 1.38 \\
\hline $2-2.5 \mathrm{~m}$ & 2 & 27.958 & 6.71 & 0.77 \\
\hline $2.5-3 \mathrm{~m}$ & 1 & 15.481 & 7.48 & 0.32 \\
\hline \multicolumn{4}{|c|}{ Jumlah } & 9.22 \\
\hline \multicolumn{4}{|c|}{$\mathrm{Cu}$ baru $=0.23 * \Sigma \mathrm{Cu}$} & 2.121 \\
\hline
\end{tabular}

Untuk penimbunan bertahap setinggi 3 meter dilaksanakan dengan kecepatan 0.5 meter/minggunya di maksudkan untuk mencapai U\% (derajat konsolidasi) maksimal perminggunya dan dibutuhkan waktu 6 minggu dengan derajat konsolidasi naik sebesar $79.46 \%$ dan dihasilkan $\mathrm{Cu}$ baru sebesar $2.121 \mathrm{t} / \mathrm{m}^{2}$. nilai ini selanjutnya digunakan dalam analisa perhitungan tahap penimbunan berikutnya hingga tinggi timbunan yang direncanakan tercapai.

Maka dilakukan analisa perhitungan peningkatan nilai $\mathrm{Cu}$ akibat penimbunan bertahap setinggi $\mathrm{H}_{\text {rencana }} 6.76 \mathrm{~m}$.

Tabel 13. Peningkatan Nilai Cu Akibat

Penimbunan Bertahap 6.76 meter

\begin{tabular}{|c|c|c|c|c|}
\hline $\begin{array}{c}\text { Tahapan } \\
\text { Penimbunan }\end{array}$ & $\begin{array}{c}\text { Umur } \\
\text { Timbunan, } t \\
\text { ( Minggu) }\end{array}$ & $\begin{array}{c}\text { Derajat } \\
\text { Konsolidasi }\end{array}$ & $\begin{array}{c}\text { Tegangan Efektif } \\
\text { Pada Lapisan } \\
\text { Yang Ditinjau Bila } \\
\text { U }=100 \%\end{array}$ & $\begin{array}{c}\text { Peningkatan } \\
\text { Nilai Cu } \\
\Delta \mathrm{P} \mathrm{Pada} \mathrm{Ui} \\
\%\end{array}$ \\
\hline Tanah Asli & & 100.00 & 2.61 & 261 \\
\hline $0-0.5 \mathrm{~m}$ & 14 & 98.29 & 3.46 & 0.83 \\
\hline $0.5-1 \mathrm{~m}$ & 13 & 97.67 & 4.30 & 3.30 \\
\hline $1-1.5 \mathrm{~m}$ & 12 & 96.83 & 5.12 & 1.75 \\
\hline $1.5-2 \mathrm{~m}$ & 11 & 95.67 & 5.92 & 3.87 \\
\hline $2-2.5 \mathrm{~m}$ & 10 & 94.09 & 6.71 & 2.62 \\
\hline $2.5-3 \mathrm{~m}$ & 9 & 90.58 & 7.48 & 4.15 \\
\hline $3-3.5 \mathrm{~m}$ & 8 & 88.99 & 8.23 & 3.48 \\
\hline $3.5-4 \mathrm{~m}$ & 7 & 84.97 & 8.97 & 4.30 \\
\hline $4-4.5 \mathrm{~m}$ & 6 & 79.47 & 9.68 & 3.90 \\
\hline $4.5-5 \mathrm{~m}$ & 5 & 71.94 & 10.38 & 3.99 \\
\hline $5-5.5 \mathrm{~m}$ & 4 & 61.63 & 11.06 & 3.49 \\
\hline $5.5-6 \mathrm{~m}$ & 3 & 47.47 & 11.73 & 2.71 \\
\hline $6-6.5 \mathrm{~m}$ & 2 & 27.96 & 12.37 & 1.43 \\
\hline $6.5-6.8 \mathrm{~m}$ & 1 & 15.48 & 13.00 & 0.58 \\
\hline \multirow{2}{*}{\multicolumn{4}{|c|}{ Jumlah }} & 43.03 \\
\hline & Cu baru & $=0.23 * \Sigma \mathrm{Cu}$ & & 9.896 \\
\hline
\end{tabular}

Pada tabel 13 dengan penimbunan setinggi $\mathrm{H}_{\text {rencana }} \quad 6.76$ meter dibutuhkan waktu penimbunan bertahap selama 14 minggu sehingga derajat konsolidasi naik sebesar 98.29\% dimana telah mendekati U $100 \%$ dengan peningkatan daya dukung tanah $\mathrm{Cu}$ sebesar $9.896 \mathrm{t} / \mathrm{m} 2$.

\subsection{Perhitungan Rencana Anggaran Biaya}

Menghitung total biaya dari alternatif konstruksi jalan menggunakan timbunan yang dibandingkan dengan penggunaan konstruksi sebelumnya yaitu tiang pancang serta plat on pile. Dengan perhitungan biaya ini dapat diperoleh alternatif penggunaan konstruksi jalan yang paling ekonomis. Perhitungan biaya dilakukan berdasarkan STA $1+050$ - STA $1+250$, akan tetapi perhitungan biaya hanya dianalisa dengan panjang jalan 10 meter saja.

Beradasarkan hasil rekapitulasi rencana anggaran biaya untuk konstruksi jalan dengan alternatif timbunan sebesar Rp. $1,124,286,000.00$ sedangkan menggun akan konstruksi jalan dengan plat on pile sebesar Rp. $1,733,627,000.00$.

\section{KESIMPULAN DAN SARAN}

\subsection{Kesimpulan}

1. Dibutuhkan $\mathrm{H}_{\text {initial }} 6.76$ meter untuk mendapatkan $\mathrm{H}_{\text {final }} 4.949$ meter, akibat dari penimbunan ini terjadi penurunan tanah total sebesar 1.82 meter.

2. Diketahui penurunan total 1.82 meter yang terjadi akibat beban timbunan, harus dihilangkan agar tidak terjadi kerusakan jalan pada saat masa layan. Apabila tanpa perbaikan untuk mencapai penurunan tanah dengan derajat konsolidasi $90 \%$ membutuhkan waktu hingga 100 tahun lamanya, hal ini menjadi salah satu alasan penulis memberikan alternatif perbaikan tanah dengan kombinasi Preloading dan Prefabricated Vertical Drain.

3. Direncanakan pemasangan PVD pola segitiga, jarak/spasi 1 meter dan kedalaman PVD sepanjang 12 meter, waktu penurunan tanah pada derajat konsolidasi $90 \%$ sebesar 7.5 minggu. Hal ini membuktikan bahwa dengan perbaikan tanah dapat mempercepat waktu penurunah tanah.

4. Dengan nilai $\mathrm{Cu}$ tanah dasar mula mula diperoleh $\mathrm{H}_{\text {rencana }}>\mathrm{H}_{\text {kritis }}$ sehingga penimbunan dilakukan secara bertahap, dengan program Plaxis 2D diperoleh SF $1.65>1.4$ nilai keamanan yang di 
syaratkan menurut buku panduan geoteknik 4. dengan kecepatan penimbunan $50 \mathrm{~cm} /$ minggu hingga mencapai tinggi timbunan yang direncana 6.76 meter dibutuhkan waktu penimbunan bertahap selama 14. minggu dengan peningkatan daya dukung tanah sebesar $9.896 \mathrm{t} / \mathrm{m}^{2}$.

5. Dari hasil perbandingan analisa rencana angaran biaya konstruksi jalan menggunakan plat on pile dan alternatif konstriksi jalan menggunakan timbunan ternyata untuk alternatif konstruksi jalan menggunakan timbunan lebih ekonomis dibandingkan menggunakan konstruksi plat on pile dimana biaya yang dibutuhkan untuk alternatif konstruksi jalan menggunakan timbunan sebesar Rp. 1,124,286,000.00 sedangkan untuk konstruksi plat on pile sebesar Rp. 1,733,627,000.00.

\subsection{Saran}

1. Perlunya dilakukan studi perbandingan antara penggunaan kombinasi metode Preloading, Prevabricated Vertical Drain dan perkuatan dengan geotextil yang bertujuan untuk mendapatkan nilai daya dukung tanah yang lebih besar sehingga tidak perlu dilakukan Preloading secara bertahap. Agar waktu tunggu selsainya konsolidasi tanah bisa lebih cepat.

2. Pada pembangunan jalan di indonesia hendaknya lebih diperhatikan besarnya Diferensial Settlement yang terjadi akibat beban selama masa layan jalan agar biaya untuk perawatan jalan yang rusak akibat beda penurunan dapat diminimalisir.

\section{DAFTAR PUSTAKA}

Das, Braja M, 1995, Mekanika Tanah (Prinsipprinsip Rekayasa Geoteknis) Jilid 1, Erlangga, Jakarta.

Hardiyatmo, H.C. 1994. Mekanika Tanah 2, Penerbit PT. Gramedia Pustaka Utama Jakarta.
Mochtar, I.B. 1994. Rekayasa Penanggulangan Masalah Pembangunan TanahTanah Yang Sulit, Jurusan Teknik Sipil, Fakultas Teknik Sipil dan Perencanaan, ITS, Surabaya.

Mochtar, Indrasurya B. 2000. Teknologi Perbaikan Tanah dan Alternatif Perencanaan pada Tanah Bermasalah (Problematic Soils). Surabaya: Jurusan Teknik Sipil FTSP-ITS.

Panduan Geoteknik 4: Disain dan Konstruksi Timbunan Jalan pada Tanah Lunak (Pusat Penelitian dan Pengembangan Prasarana Transpor- tasi, DPU, 2001).

Soedarmo G. D., dan Purnomo, S.J.E. 1997. Mekanika Tanah 1 dan Mekanika Tanah 2, Penerbit Kanisius.

Terzaghi, K dan R.B. Peck. (1987), Mekanika Tanah dalam Praktek Rekayasa I, Alih bahasa Bagus, W., dan K. Benny. Erlangga, Jakarta. 